\title{
Ginger-induced Ileal Motility is Modified by Stress: Sex Differences in Rats
}

\author{
Mari Kimoto ${ }^{1}$, Jorge L. Zeredo ${ }^{3,4}$, Masato S. Ota ${ }^{2}$, Zenro Nihei ${ }^{4}$, Kazuo Toda ${ }^{1,4,}$ * \\ ${ }^{1}$ Physiological Laboratories, Japan Women's University, Tokyo, Japan \\ ${ }^{2}$ Laboratory of Biochemistry and Food Biology, Japan Women's University, Tokyo, Japan \\ ${ }^{3}$ Graduate Program in Health Sciences and Technologies,University of Brasilia, Brasilia, Brazil \\ ${ }^{4}$ Integrative Sensory Physiology, Graduate School of Biomedical Sciences, Nagasaki University, Nagasaki, Japan
}

Email address:

k-toda@nagasaki-u.ac.jp (K. Toda)

\section{To cite this article:}

Mari Kimoto, Jorge L. Zeredo, Masato S. Ota, Zenro Nihei, Kazuo Toda. Ginger-induced Ileal Motility is Modified by Stress: Sex Differences in Rats. Journal of Food and Nutrition Sciences. Special Issue: Effects of Foods on Gastrointestinal, Metabolic and Immunological Function. Vol. 3, No. 3-1, 2015, pp. 5-8. doi: 10.11648/j.jfns.s.2015030301.12

\begin{abstract}
Ginger is widely used as a spice and also an effective herbal medicine to treat gastrointestinal disorders. On the other hand, stress can induce various modulation of digestive motility. Here, we investigated ginger effects on stress-induced motility of the isolated ileum in male and female rats, in vitro. Rats (Wistar, SPF, 7-12 weeks of age, 148-393 g BW) were divided into Control (1G) and 3G groups. 3G stress (every day for $10 \mathrm{~min}$ ) was loaded by centrifugal apparatus for 1, 3, 15 and 30 days. After the stress loading at each day, a $1 \mathrm{~cm}$-long section of the ileum was isolated under barbiturate anesthesia and fixed to a Magnus-type chamber filled with Tyrode solution. Ileal movements were observed for $60 \mathrm{~s}$ following application of zingerone, which is also called vanillylacetone and a key component of the pungency of ginger $(0.1-10 \mu \mathrm{M})$. Spontaneous motility movements with phasic and tonic patterns were observed in the ileum. The former was a peristalsis-like movement and the latter was a slow fluctuation of the baseline. Ginger induced enhanced effects on the rhythmic phasic motility in relation to amplitude. In the female, $3 \mathrm{G}$ gravity loading had no effects on the ginger-induced motility, however, suppressive effect of the ginger-induced phasic movements was clearly observed at day 15 in the male. The present study showed that gravity stress changed ginger-induced effects on phasic ileal motility in the male, but not in the female, indicating that sex differences were observed in the ginger effects modulated by stress loading.
\end{abstract}

Keywords: Ginger, Zingerone, Ileum, Motility, Sex Difference, Rat

\section{Introduction}

Ginger, the root of Zingiber officinale, is widely used as a spice and an effective herbal remedy for various symptoms [1]. As a traditional herbal plant, ginger has been used for 4000 years in various manipulations, such as fresh ginger, dried ginger or roasted ginger [2,3]. For example, ginger can alleviate the aches and pains of anticancer chemotherapy treatment $[3,4]$, or act as an anti-inflammatory agent, easing the symptoms of arthritis and other joint conditions [5]. Furthermore, ginger has a powerful antiviral action and is a great remedy for colds [6].

In Japan, ginger is prescribed as a Kampo medicine to treat mild digestive complaints [7]. It can help to treat gastrointestinal diseases, including nausea and vomiting from motion sickness, diarrhea, loss of appetite, and dry mouth

\section{[8,9].}

In animal studies using rats, Borrelli et al. [10] reported using an in vitro preparation, that ginger possess inhibitory effects on ileal motility evoked by electrical and acetylcholine stimuli. Interestingly, the inhibitory effect of ginger on ileum contractions was reduced by the vanilloid receptor antagonist capsazepine [10]. By contrast, other reports show that ginger enhances electrically evoked ileal motility in guinea pigs [11] and natural ileal motility in mice [12]. Therefore, effects of ginger on the ileal motility are still controversial.

Stress, on the other hand, has a strong negative effects on the digestive function in humans and animals [13]. In rats, the severity of the stressor may critically influence the pattern of feeding behavior. For example, chronic and strong stress induced decrease of food intake and loss of body weight [14], whereas mild stress increased food intake, 
especially that of highly palatable foods [15-18]. It is also reported that stress strongly modified ileal motility and that there were sex differences in the effects of stress-loading $[19,20]$.

However, it is not known whether ginger has significant effects on the stress-loading changes of the ileal movement. In the present study, we evaluated in vitro the effects of ginger application on the stress-modified ileal movements of rats. Sex differences were examined by using separate groups of male and female rats.

\section{Methods}

The methods described here follow the ethical guidelines and received approval by the Animal Welfare Committee of Japan Women's University. Detailed methods are reported in our previous paper [21].

A total of 128 rats of both sexes (Wistar, SPF, 7-12 w. of age, 148-393 g BW) were divided into Control (1G) and 3G groups. $3 \mathrm{G}$ stress (every day for $10 \mathrm{~min}$ ) was loaded by a centrifugal apparatus for 1, 3, 15 and 30 days.

For the in vitro preparation, a $1 \mathrm{~cm}$-long portion of the ileum was isolated under barbiturate anesthesia (Nembutal, 20 $\mathrm{mg} / \mathrm{kg}$, i.p.). The inner contents of the isolated ileum were washed away with Tyrode solution. After that, the isolated ileum was fixed into a Magnus-type chamber filled with Tyrode solution (temperature: $37^{\circ} \mathrm{C}$ ) as reported elsewhere [22]. The proximal end of the preparation was set upward and connected to a strain gauge through a cotton thread (Daruma \#30, Yokoi, Osaka, Japan). The distal end of the preparation was fixed to the bottom of the chamber. Ileal movements were amplified by a strain-gauge amplifier (x100) and recorded continuously on a pen-recorder (SS259F2, SEKONIK, Tokyo, Japan). Ileal movements were observed for $60 \mathrm{~s}$ following application of zingerone $(1 \mu \mathrm{M})$, a phenolic substance isolated from the rhizome of ginger and obtained from Wako Pure Chemical Industries (Osaka, Japan).

In this study, spontaneous peristaltic movements were obtained in all preparations, therefore, electrical or chemical (acetylcholine) stimulation were not need to evoke ileal movement. Zingerone solution $(0.3 \mathrm{ml})$ was topically applied onto the ileum preparation using an injection syringe. Ileal movements were estimated using the magnitudes of the peak-to-peak amplitudes of the phasic contraction. Relative amplitudes of the ileal contraction were calculated by normalizing the amplitudes of just before zingerone application to the value of 1.0 . $3 \mathrm{G}$ stress was loaded by a centrifugal apparatus (H26-F, Kokusan, Tokyo, Japan) every day at 10:00 AM for $10 \mathrm{~min}$ during 30 days, as described elsewhere [22]. During loading, rats were placed in the mesh case of the centrifuge with tail-central orientation. In the control (1G) group, the rats were placed in the centrifuge but no gravity-loading was applied.

Significant differences were determined by using unpaired t-test. $\mathrm{P}$ values of less than 0.05 were considered statistically significant. All data are expressed as means \pm SEM.

\section{Results}

Zingerone modified spontaneous peristaltic movements of rats after 15 days of stress conditioning. Typical exemples are shown in Figures 1 and 2. Zingerone was applied at the time of upward arrows. In the case of males (Fig. 1), zingerone gradually enhanced phasic ileal movements in control (upper trace), but in 3G-loading rats, the movement-enhancing effect of zingerone was suppressed (lower trace). By contrast, in female rats (Fig. 2), zingerone clearly enhanced spontaneous peristalsis movements in control, the same as in the male rat; however, there were no significant changes in the phasic amplitudes of peristalsis after $3 \mathrm{G}$ loading.

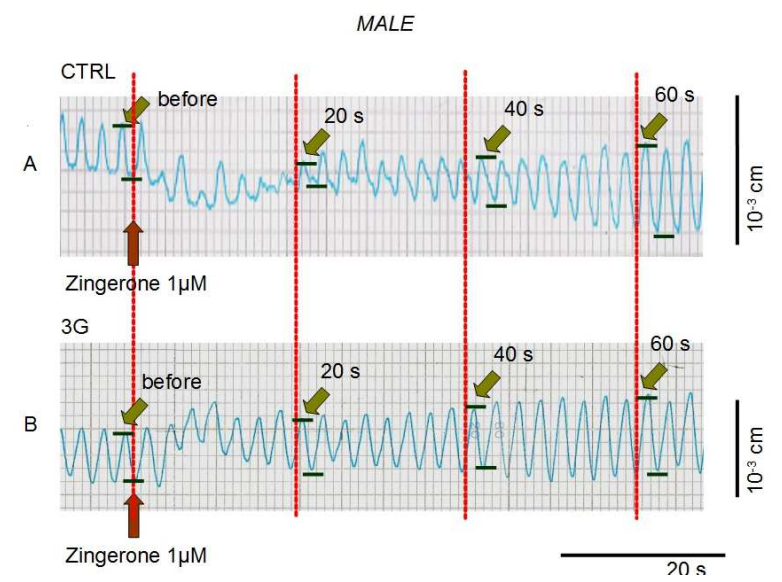

Figure 1. Typical example of the effects of zingerone on the ileum movements under stress-free $(A)$ and $3 G$-stress loadings $(B)$ in male rat.

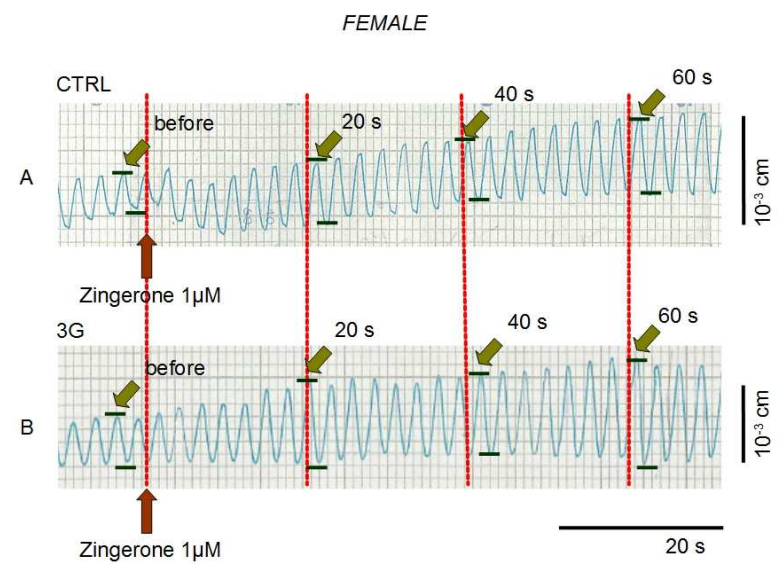

Figure 2. Typical example of the effects of zingerone on the ileum movements under stress-free $(A)$ and $3 G$-stress loadings $(B)$ in female rat.

Figures 3 and 4 summarize the zingerone effects on the stress-modified peristalsis movements in male (Fig. 3) and female (Fig. 4) at day 15 of stress conditioning. Zingerone-induced phasic contraction was suppressed after $3 \mathrm{G}$ loading in male but not in female rats.

At 1,3 and 30 days of stress conditioning, significant differences of zingerone effects on the ileal movements between control and $3 \mathrm{G}$ groups were not observed in either male or female rats. 


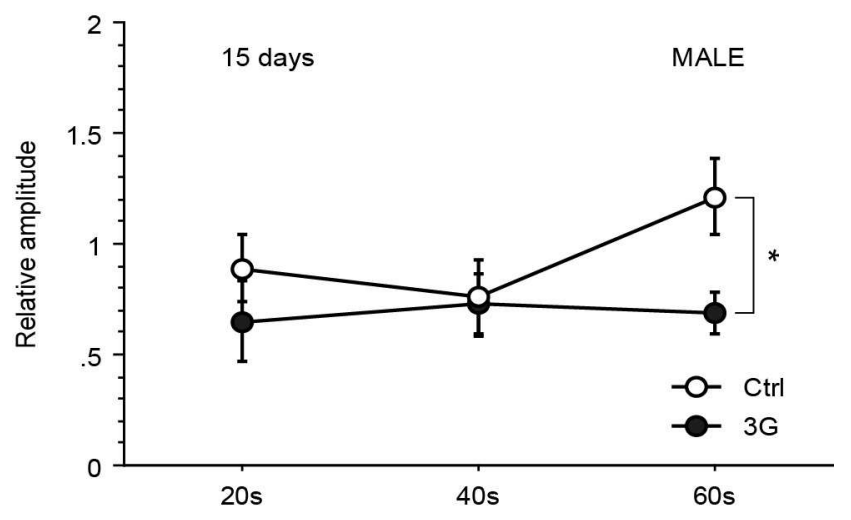

Figure 3. Changes in relative amplitudes of the ileum contraction 20, 40 and $60 \mathrm{~s}$ after zingerone application in male rats. Amplitudes are calculated as (amplitudes at 20,40, $60 \mathrm{~s}$ ) / (amplitude just before zingerone application). Significant difference $(P<0.05)$ between control (stress-free) and $3 G$-stress loading groups was observed at $60 \mathrm{~s}$.

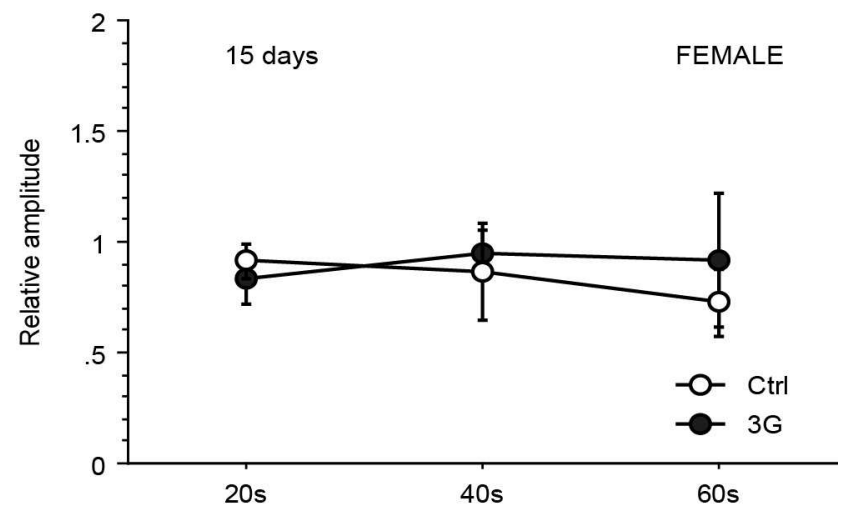

Figure 4. Changes in relative amplitudes of the ileum contraction 20, 40 and $60 \mathrm{~s}$ after zingerone application in female rats. There were no significant differences between control (stress-free) and $3 G$-stress loading groups.

\section{Discussion}

Various herbal vegetables and spices are quite useful for cooking in the world [23]. In addition, these materials are also useful in traditional medicine in Asian countries. Indeed, ginger is the most popular one, and therefore it is important from a nutritional perspective to clarify the effects of ginger on the digestive function [24].

In this study, we showed that ginger enhanced ileum motility in both sexes and that this enhancement was weakened after stress loading in males. This suggests that zingerone sensitivity may decrease after stress loading in males, but not in females.

There are increasing data about sex differences in the stress response on the various physiological functions. Special attention has been paid on the feeding behavior after various stress loadings. In human studies, strong stress decreases body weight in both sexes; however, weak stress may sometimes decrease or increase body weight [25-27].

In animal studies using rats, our previous data showed that sex differences can be observed in stress-induced ileal movements $[21,22]$ One of the possible explanations for sex differences is the critical endocrinological differences in response to stress between male and female on various physiological functions, including digestion [20,25].

On the other hand, herbal medicine is frequently used in subliminal clinical treatment [28,29]. In digestive system, ginger is reported to have a good facilitatory effects on the digestive problems in human [8].

Basic animal studies showed that intestinal travel of charcoal meal was enhanced in mice and in guinea pigs, indicating that ginger enhanced ileal motility [11]. Our study also showed that zingerone, a ginger extract, enhanced ileal motility. By contrast, Borrelli et al. [10] reported the Inhibitory effect of ginger on rat ileal motility in vitro. These discrepancies may be due to differences of methods, that is, they induced ileal motility by electrical or acetylcholine stimuli, whereas such stimuli was not used in our study. We analyzed ginger effects on spontaneous ileal movements only. The mechanisms of the inhibitory effects observed after stress loadings in the male rats were unclear; however, one of possible explanation is due to a decrease in acetylcholine transmission after stress. We observed inhibitory effects only at 15 days after stress loading, and not at 1,3 or 30 days. This may be due to slow changes in neuronal plasticity, and adaptation against stress. Indeed, stress-induced mechanisms for neuronal plasticity on several receptors, such as 5-HT, histamine, TRPV1, TRPM1 and opioids needed to be clarified by further experiments [30-33].

In conclusion, the present study showed that gravity stress changed ginger-induced facilitation on phasic ileal motility in the male, but not in the female, indicating that sex differences may be present in the ginger effects modulated by stress loading.

\section{Acknowledgment}

This study was supported by JSPS grants (No.25350146, 26350147).

\section{References}

[1] Malhotra, S., Singh, A.P. (2003). Medicinal properties of Ginger (Zingiber officinale Rosc.). Natural Product Radiance 2:296-301.

[2] Thomson, M., Al-Qattan, K.K., Al-Sawan, S.M., Alnaqeeb, M. A., Khan, I., Ali, M. (2002). The use of ginger (Zingiber officinale Rosc.) as a potential anti-inflammatory and antithrombotic agent. Prostaglandins Leukot Essent Fatty Acids. 67:475-458

[3] Pereira, M.M., Haniadka., R, Chacko, P.P., Palatty, P.L., Baliga, M.S. (2011). Zingiber officinale Roscoe (ginger) as an adjuvant in cancer treatment: a review. J Buon.;16:414-424.

[4] Haniadka,R., Rajeev,A.G., Palatty,P.L., Arora, A., Baliga,M.S., (2012). Zingiber officinale (Ginger) as an anti-emetic in cancer chemotherapy: A Review. J. Altern. Complementary Med. 18: 440-444.

[5] Ramadan, G., Al-Kahtani, M.A., El-Sayed W.M. (2011). Anti-inflammatory and anti-oxidant properties of Curcuma longa (turmeric) versus Zingiber officinale (ginger) rhizomes in rat adjuvant-induced arthritis. Inflammation. 34:291-301. 
[6] Changa, J. S.; Wanga, K. C.; Yehd, C. F.; Shiehc,D.E.; Chiang, L. C. (2013). Fresh ginger (Zingiber officinale) has anti-viral activity against human respiratory syncytial virus in human respiratory tract cell line. J.Ethnopharmacol., 145:146-151.

[7] Suzuki, H., Inadomi, J.M., Hibi, T. (2009). Japanese herbal medicine in functional gastrointestinal disorders.] Neurogastroenterol Motil. 21: 688-696.

[8] Ghayur, M.N., Gilani, A. H. (2005). Pharmacological basis for the medicinal use of ginger in gastrointestinal disorders. Dig Dis Sci. 50:1889-1897.

[9] Jalali-Nezhad, A. A., Farajian-Mashhadi, F., Komeili, G., Barkhordari-Ahmadi, F. (2015) The effect of ginger hydroalcholic extract on rat ileal contraction in vitro. Zahedan J Res Med Sci. 15:29-33.

[10] Borrelli, F., Capasso, R., Pinto, A., Izzo, A.A. (2004). Inhibitory effect of ginger (Zingiber officinale) on rat ileal motility in vitro. Life Sci. 74:2889-2896.

[11] Sato, K., Kase, Y., Hayakawa,T., Murata, P., Ishige, A., Sasaki, H. (2001). Dai-kenchu-to enhances accelerated small intestinal movement. Biol. Pharmaco. Bull., 24:1122-1126.

[12] Yamahara, J., Huang, Q., Li, Y. H., Xu, L., Fujimura, H. (1990). Gastrointestinal motility enhancing effects of ginger and its active constituents. Chem.Phramaco. Bull., $38: 430-431$

[13] Mayer, E. A. (2000). The neurobiology of stress and gastrointestinal disease. Gut, 47:861-869.

[14] Marti, O., Marti, J., Armario, A. (1994). Effects of chronic stress on food intake in rats: Influence of stressor intensity and duration of daily exposure. Physiology \& Behavior, 55:747-753.

[15] Torres, S. J., Nowson, C. A. (2007). Relationship between stress, eating behavior, and obesity. Nutrition. 23:887-894.

[16] Marti O, Marti J, Armario A. (1994). Effects of chronic stress on food intake in rats: influence of stressor intensity and duration of daily exposure. Physiol. Behav. 55:747-53.

[17] Rowland, N. E., Antelman, S. M. (1976). Stress-induced hyperphagia and obesity in rats: a possible model for understanding human obesity. Science 191:310-312.

[18] Wallach, M. B., Dawber, M., McMahon, M., Rogers, C. (1977). A new anorexigen assay: stress-induced hyperphagia in rats. Pharmacol. Biochem. Behav. 6:529-531.

[19] Machado, T. D., Dalle Molle, R., Laureano, D. P,. Portella, A.K., Werlang, I. C., Benetti C. da, S., Noschang, C., Silveira, P. P. (2013). Early life stress is associated with anxiety, increased stress responsivity and preference for "comfort foods" in adult female rats. Stress 16:549-556.

[20] Lucassen, P. J., Pruessner, J., Sousa, N., Almeida, O. F., Van Dam, A. M., Rajkowska, G., Swaab, D. F., Czéh, B. (2014). Neuropathology of stress. Acta Neuropathol. 127:109-135.
[21] Kimoto, M., Zeredo, J. L., Ota, M. S., Nihei, Z., Toda, K.(2014). Comparison of stress-induced modulation of smooth-muscle activity between ileum and colon in male rats, Auton. Neurosci., 183:8-11.

[22] Kimoto, M., Zeredo, J. L., Toda, K. (2012). Hypergravity conditioning on ileal movements in rats. Aviat. Space Environ. Med. 83:483-487.

[23] Edwards, Q. T., Colquist, S., Maradiegue, A. (2005). What's cooking with garlic: is this complementary and alternative medicine for hypertension? J Am Acad Nurse Pract. 17:381-385.

[24] Hoffman, T. (2007). Ginger: an ancient remedy and modern miracle drug. Hawaii Med J. 66:326-327.

[25] McEwen, B. S. (2011). Stress, sex and neural adaptation to a changing environment: mechanisms of neuronal remodeling. Ann. N. Y. Acad. Sci. 1204 (Suppl): 38-59.

[26] Maniam, J., Morris, M. J. (2012). The link between stress and feeding behaviour. Neuropharmacol. 63:97-110.

[27] Yau, Y. H., Potenza, M. N. (2013). Stress and eating behaviors. Minerva Endocrinology 38:255-267.

[28] Keatonga, L., Hayesa, J., Moanea, S., Lehaneb, M., O'Dohertyc, S., Kingstond, R., Fureyb, A. (2014). The effect of simulated gastro-intestinal conditions on the antioxidant activity of herbal preparations made from native Irish hawthorn. J. Herbal Med. 4:127-133.

[29] Allisona, D. B., Fontaineb, K. R., Heshkaa, S., Mentorec, J. L., \& Heymsfieldc, S. B. (2001). Alternative treatments for weight loss: A critical review. Critical Reviews in Food Science and Nutrition. 41:1-28.

[30] McNamara, F. N., Randall, A., Gunthorpe, M. J. (2005). Effects of piperine, the pungent component of black pepper, at the human vanilloid receptor (TRPV1). Br. J. Pharmacol.144:781-790.

[31] Geppetti, P., Trevisani, M. (2004). Activation and sensitisation of the vanilloid receptor: role in gastrointestinal inflammation and function Br. J. Pharmacol. 141: 1313-1320.

[32] Mundey, M. K., Ali, A., Mason, R., Wilson, V. G. (2000). Pharmacological examination of contractile responses of the guinea-pig isolated ileum produced by m-opioid receptor antagonists in the presence of, and following exposure to, morphine. Br J Pharmacol. 131:893-902.

[33] Pertz, H. H., Lehmann, J., Roth-Ehrans, R., Elz, S. (2011). Effects of ginger constituents on the gastrointestinal tract: Role of cholinergic M3 and serotonergic 5-HT3 and 5-HT4 receptors. Planta Med. 77:973-978. 